\title{
Planned Dose Unit
}

National Cancer Institute

\section{Source}

National Cancer Institute. Planned Dose Unit. NCI Thesaurus. Code C82581.

The unit of measure for an intended exposure. 